Lisbon - Malacca Port Cities Twin Conferences 2019 / 2020

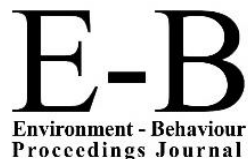

AicQoL2020Malacca

ASLI (Annual Serial Landmark International) Conferences on QoL2020

https://www.amerabra.org; https://sspu.uitm.edu.my/cebs; https://www.emasemasresources.com/

8th AMER International Conference on Quality of Life

Mahkota Hotel Melaka, Malacca, Malaysia, 18-19 Mar 2020

(Due to the Covid-19 lockdown, paper virtually presented on 25 Mar 2020)

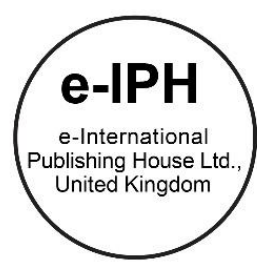

\title{
Parking Spaces in Taylor's University: Problems and solutions
}

\author{
Filzani Illia Ibrahim, Muhammad Fareez, Myzatul Aishah Kamarazaly \\ School of Architecture Building and Design, Faculty of Innovation and Technology, \\ Taylor's University, Malaysia \\ filzanillia@gmail.com; fareezsham@yahoo.com; MyzatulAishah.Kamarazaly@taylors.edu.my; \\ Tel: +60136365208
}

\begin{abstract}
Parking is an essential component of the transportation system. Insufficient parking spaces provided brings many problems to the campus society as well as to the environment such as congestion, high accident rate; shortage of parking spaces, low air quality and high maintenance cost to maintain the transportation infrastructure and facilities. The objective of this paper is to evaluate the satisfaction of the parking facilities provided by Taylor's University hence proposing a solution to the issue. The outcome of this research is to benefit the student and staff that are driving and park their vehicles at Taylors University parking facilities.
\end{abstract}

Keywords: parking; sustainability; facilities management

eISSN: 2398-4287 @ 2020. The Authors. Published for AMER ABRA cE-Bs by e-International Publishing House, Ltd., UK. This is an open access article under the CC BYNC-ND license (http://creativecommons.org/licenses/by-nc-nd/4.0/). Peer-review under responsibility of AMER (Association of Malaysian Environment-Behaviour Researchers), ABRA (Association of Behavioural Researchers on Asians) and cE-Bs (Centre for Environment-Behaviour Studies), Faculty of Architecture, Planning \& Surveying, Universiti Teknologi MARA, Malaysia. DOI: https://doi.org/10.21834/e-bpj.v5i13.2035

\subsection{Introduction}

Parking is an essential component of the transportation system. It is increasingly becoming a necessary aspect of transportation planning (M R Rajashekara et al., 2014). Parking facilities are a high cost to society, and parking conflicts are among the most common problems facing designers, operators, planners and other officials. Public parking spaces, as one of the essential parts of a modern urban transportation system, plays a vital role in decreasing the load of heavy traffic. Proper site selection for public parking spaces not only increases the parking efficiency, but it also reduces limited car parking and so results in an increase of streets' width and traffic fluency. In the absence of adequate parking facilities, the vehicles are parked on the side of the road leading to a significant bottleneck in the smooth flow of traffic. Nowadays, two-wheeler or car parking steals the most valuable asset every individual has, i.e. time. A lot of time is wasted in finding for an available parking space. Lack of parking spaces is an additional source of traffic congestion and pollution. More traffic means more pollution. Vehicle's CO2 emission is higher while you are circling looking for an available parking spot than you could just drive to your place and park the car (Rajat Boob \& Arjita. Biswas, 2018).

\subsection{Literature Review}

Parking is a widespread problem that happened in the majority of the urban areas in the world. The rise of the human population contributes to the increase in demand while the supply is decreasing. In so many years, engineers and planners have come out with a variety of ways on how to overcome this problem. Just like the urban areas, universities are also facing this kind of problem. Each

eISSN: 2398-4287 @ 2020. The Authors. Published for AMER ABRA cE-Bs by e-International Publishing House, Ltd., UK. This is an open access article under the CC BYNC-ND license (http://creativecommons.org/licenses/by-nc-nd/4.0/). Peer-review under responsibility of AMER (Association of Malaysian Environment-Behaviour Researchers), ABRA (Association of Behavioural Researchers on Asians) and cE-Bs (Centre for Environment-Behaviour Studies), Faculty of Architecture, Planning \& Surveying, Universiti Teknologi MARA, Malaysia.

DOI: https://doi.org/10.21834/e-bpj.v5i13.2035 
semester, the intake of students is getting more and more, causing a higher demand on the campus. Figure 1 shows a comparison between student enrolments in 2011 and 2014 in a few local universities.

Based on the statistics, the number of students enrolled in 2014 is higher than in 2011. The number of transportation users will be increased. This is why parking needs to be managed well in all universities. Parking management is a program to improve the utilising of current parking spaces (Bowerman, 2006). Besides that, Litman (2006) stated that the parking management could also reduce the demand, traffic and pollution, and to provide more accessible lands and significant financial savings (Muhammad Izhar Bin Bakhtiar, 2015).

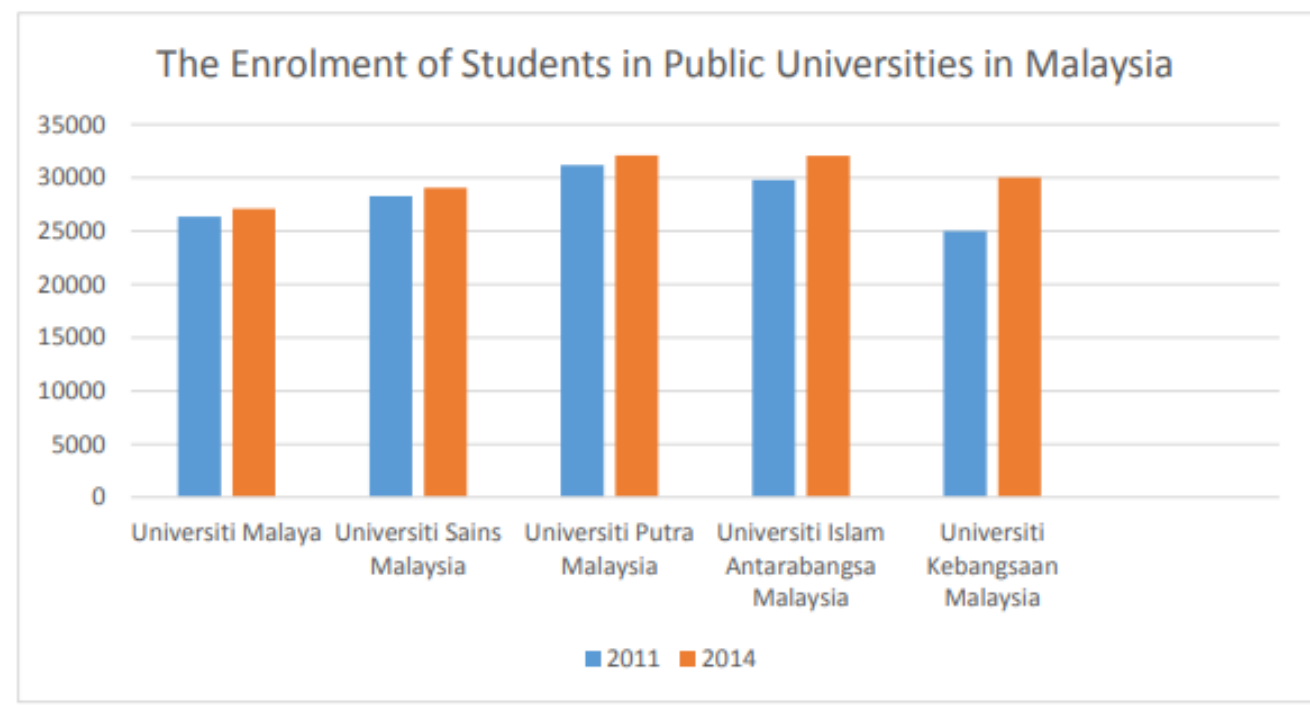

Figure 1: Enrolment of students in public university in Malaysia

\subsection{Determination of Parking Availability}

The number of parking spaces demanded is mostly defined by the parking requirements stipulated in the zoning code. It is therefore expressed as a unit space per square unit of an area. Litman (2012b) suggests this method of providing indexes or ratios for parking gives unconstrained and unadjusted values. Hence, such indexes or rates only reflect the maximum supply that could be needed (ibid) and often adjusted significantly downward (Topp, 2009). Instead, it only seeks to clarify the position that, existing parking models mostly lean towards an overestimation of what needs to supply. Without considering the location, land uses, alternative transportation options, and most importantly, the parking prices, parking policies might overestimate the demand and hence the supply. And when this occurs, the costs and benefits results are quite apparent, especially when indirect costs like stormwater management and other environmental consequences are factored into the equation (Emmanuel Frimpong Boamah, 2013).

Generally, the ratio is calculated by dividing the number of vehicle parking spaces into the building's square footage and expressing the result per 1,000 square feet. Take a retail plaza with 300 parking spots and 60,000 square feet of shopping space. To calculate the parking ratio, divide 300 by 60 . The result is five parking spots for every 1,000 square feet of floor space in the plaza. It's that simple (Neil Kokemuller, 2019). For example, a requirement of three areas per 1,000 ft2 implies that more space must be committed to parking than to useable building space. To meet parking requirements, therefore, developers must either reserve a more substantial portion of land for parking, which often means having less for useable building space or make considerable investments in multilevel parking structures to make more efficient use of the available area. Figure 1 depicts the relationship between building space and parking space for a series of scenarios.

\subsection{The Impact of Dearth of Parking in University}

"A student's parking has always been an issue for Commuter Students. The lack of available spaces in parking lots, and the lack of parking lots around campus has caused many students to feel frustrated. Yet commuter students and resident students face similar issues (Commuter students, 2013). One problem both types of students face are the size of the parking spaces in the available parking lots. Resident and commuter students are required to park in their designated parking lots, even though sometimes they fear parking there because of the size of the available spaces. Parking lots tend to be very small, and therefore very hard to drive in. If students aren't careful, they could easily hit another car, light pole, or make a hole in a gravel lot too fast and cause damage to their vehicle. Students also have to be careful when trying to fit into the tiny parking spaces in these lots.

With a vast number of students commuting to campus and not nearly enough parking, the university needs to find new ways to accommodate commuters as it increasingly affects a student's ability to learn. According to a Feb. 19 Northern Star poll, 71 out of 80 students, or 88 percent, said they have been late to a class due to parking issues. It is unreasonable for parking to be an obstacle to academic success. The lack of student spots results in students being late to class or tests and potentially losing points, whereas teachers can be new without penalty. Students need more than just the reallocation of a few spots. To ease the burden of this issue, the university should consider another location for a lot. Lincoln Hall has been condemned for years and does nothing but take up space. 
While this could be costly, the university should consider turning the area into a yellow lot as it could be the difference between students going to class or not. Until serious changes are made, students will have to continue to struggle to park and will probably continue to be late or choose not to attend because of inadequate parking options. Student parking needs serious help, whether it be reallocating spots or finding somewhere to build another lot.

When all the parking lots are taken up, lecturers or students have no choice but to park illegally which results in their cars getting clamped, and to unclamped their cars, a fine of RM25 will have to be paid. A university staff car was clamped for parking at the side of a taken parking lot where he had no choice as there are no vacant spots available. Numerous suggestions were given to improve the situation by various staff such as designated parking lots for motorcycles, a multi-story car park, expanding the land to make more parking bays, etc. The lack of parking bays for universities has resulted in numerous complaints, and suggestions have been given to improve the situation, but no action has been taken so far (George,2016). Hence, the objective of this paper is to evaluate the satisfaction of the parking facilities provided by Taylor's University thus proposing a solution to the issue. The outcome of this research is to benefit the student and staff that are driving and park their vehicles at Taylors University parking facilities.

\subsection{Methodology}

The approach selected for this analysis is a quantitative method. Questionnaires were used as the instrument for collecting the primary data for this analysis. The surveys include straight questions. It is made up of four parts. Section A serves to understand the students' profile and background. The key to this section is also to identify whether the respondents are Taylors University students. It is essential to understand the history of the respondents to gather more accurate information. The respondents should be students in Taylors University who are driving to campus and experience the parking problems. Section B, the purpose of this section is to identify the level of satisfaction of demand for parking space provided in Taylors University. This section also serves to understand the difficulties of students to obtain a parking space which will help to understand the demand for parking space in Taylor's University. Section $\mathrm{C}$ plays a role to follow the performance of the parking facility in Taylor's University. This section also attempts to understand what the facility is lacking in Taylor's University and should be enhanced. Section D serves the purpose of providing a solution of for both Section $C$ and Section D. This section offers the best solution for the parking demand and facility which can help satisfy the students in Taylor's University. Before handing out the questionnaires, the number of students in Taylors must first be identified. Based on the email that I had received upon enquiry from Taylor's campus central on September 2019, approximately 11,000 students study at this university. Three hundred eighty-one survey forms were given out to the students as the requires sampling size that had been calculated.

\subsection{Findings}

The scope of this research is limited to only Taylors University Lakeside Campus students. The questionnaire is focused on the Taylors University parking facility and the problems of student faced regarding the parking quantity in Taylor's University. It also asks respondents on their view on the current condition of Taylor's University parking and the solution that can be implemented to improve the parking issues. Three hundred eighty-one survey forms were distributed out to the students as the requires sampling size and 381 responses were successfully obtained.

\subsection{Issues of Demand Parking Spaces Available in Taylor's University}

The first objective is to identify the issues of demand parking spaces available in Taylors University. According to the results from the survey, $74.7 \%$ of the respondents are not satisfied with the parking spaces provided by Taylor's University. $70.9 \%$ of the respondent agreed that it is hard for them to obtain parking at Taylor's University. Results also show that $49.6 \%$ of the respondents strongly agree that there should be more parking spaces added at Taylor's University. Other than that, $73 \%$ of student or respondents spent $15-30$ minutes looking for a parking spot at Taylor's University. This will help to conclude that there a not enough parking space provided which makes the students spent most of their time driving around looking for a parking spot. $65.3 \%$ of the respondent strongly agrees that there should be a better parking system in order for the students to obtain a parking space. From results and data gathered, it can be concluded that most of the respondents are not satisfied with the parking supply in Taylor's University, which the student demand for more parking space.

Table 1: Issues of Parking Spaces Available in Taylor's University

\begin{tabular}{lll}
\hline Questions & Percentage (\%) & Mean \\
\hline Does the parking spaces provided in Taylor's University satisfying? & 74.7 & 3.87 \\
Is it difficult for you to obtain parking in Taylor's University? & 70.9 & 2.08 \\
Should there be more parking spaces added in Taylor's University? & 49.6 & 1.65 \\
Should there be a better parking system? & 65.3 & 1.38 \\
Do you find any vehicles that are parked illegaly? & 46.1 & 1.75 \\
\hline
\end{tabular}

\subsection{Problems of Parking Facilities in Taylor's University}

The second objective is to determine the problems of parking facilities at Taylor's University. The results of the respondent are shown on the Likert scale, which shows the Agreement or disagreement of the respondent towards the question asked. According to the results from the survey, $72.3 \%$ of the respondents disagree that the parking facility provides a proper parking guideline. $76.1 \%$ of the respondents agreed that the walking distance from the parking zone to the main campus too far. $53.3 \%$ of the respondent strongly 
agree that the parking facility provided could damage their vehicle. Regarding the matter of should the parking facility be shaded, $59.7 \%$ of the respondent strongly agrees that it should be shaded. $67.7 \%$ of the respondents strongly agree that the parking facility is in reduced maintenance and condition. In conclusion, the parking facilities in Taylors University is not well maintained, and the parking facility provided by the university does not satisfy the students where the students think the parking facility should be in a better condition where the students can park their vehicle daily.

Table 2: Problems of Parking Spaces Facilities in Taylor's University

\begin{tabular}{lll}
\hline Questions & Percentage (\%) & Mean \\
\hline Does the parking facilities provide a proper parking guideline? & 72.3 & 3.72 \\
Is the walking distance from the parking zone to the main campus too far? & 76.1 & 1.90 \\
Do you think the parking facility provided could damage your vehicle? & 53.3 & 1.53 \\
Should the parking facilities be shaded & 67.6 & 1.43 \\
Is the parking facility in poor maintenance and condition? & 56.6 & 1.37 \\
Should there be a shaded walkway for students to walk from campus to the parking zone? & 1.44 \\
\hline
\end{tabular}

\subsection{Solutions and Recommendations of Parking Demand and Facilities in Taylor's University}

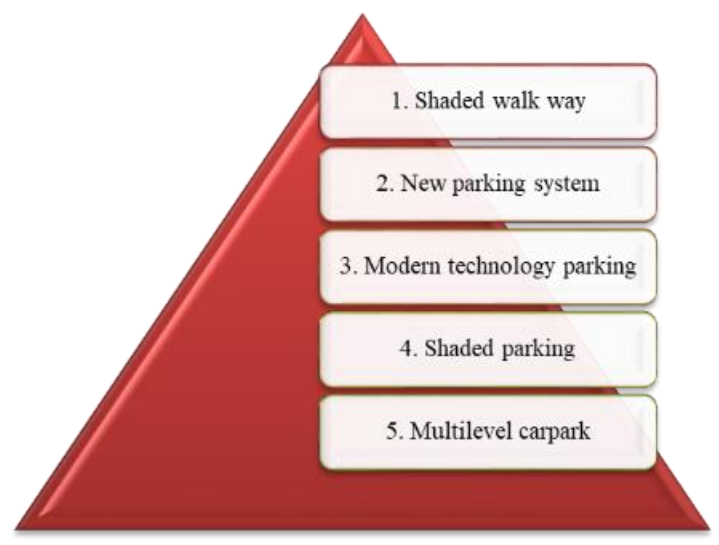

Figure 2: Ranking of parking solution

According to the results from the survey, the highest requested solution for parking in Taylors University is the students would like to have a shaded walkway from the campus to the parking zones. The second highest is a new parking system which will help students to know how many parking spots are available at each parking zones around the campus which is shown in Figure 2 . The third will be the modern technology parking management which will provide the latest technology update of a parking system at the parking zone. The fourth is the Shaded parking which will provide a canopy parking shade to protect the vehicle from the sun or rain. The last requested solution is a multilevel car park which will help increase the parking capacity in a specific size of land. This objective is to recommend solution \& improvements of parking demand \& facilities in Taylors University. According from the results from the survey, $43.2 \%$ of the respondents strongly agree that by implementing these multilevel car park systems, it help solve the parking problems in Taylor's university. $49.7 \%$ of the respondents agree that if the free student car park is shaded will it encourage them to park there. $63.1 \%$ of the respondents strongly agreed that a new parking system which will let them know about how many parking spots are available at each lot is recommended, which can help them obtain parking. Other than that, the respondents strongly agree that there should be a modern and high technology parking management system which can solve the parking issues at Taylors University. Since Taylors University does not provide a shaded walkway to the parking zones, the students strongly agree that there should be a shaded walks way. In conclusion, the respondents are willing to accept any solution to the parking demand \& facilities in Taylors University which can help the respondents to obtain a parking space and park their vehicle in a safe condition daily.

Hence, among the solutions are the automated parking system which is a mechanical system designed to minimise the area and volume required for parking cars. Like a multi-story parking garage, an automated parking system provides parking for cars on multiple levels stacked vertically to maximise the number of parking spaces while minimising land usage. This parking system utilises a mechanical system to transport vehicles to and from parking spaces (rather than the driver) to eliminate much of the space wasted in a multi-story parking garage.

\section{a) Save Space and Money}

A typical parking garage is constructed to allow cars enough room to safely circulate in both directions and back out of parking spaces. In an automated garage, this circulation space is not required, and neither is space to open car doors. This helps developers better utilise the area that would typically be used for cars and people to move around, and allows more storage space for vehicles in that space using single-deep or double-deep storage configurations. 


\section{b) Lower Operational, Construction and Finishing Costs}

Pallet less automated garages allow developers to save on construction costs through reduced excavation, reduced construction time and lower land costs. A sizeable potential operation saving is in valets or operator salaries, insurance, $\mathrm{HR}$, hiring and benefits fees since they are typically not required in an automated garage. Lower ventilation costs are achievable due to the reduced requirement of only two air changes per hour for automated parking systems.

\section{c) Increase Customer Satisfaction}

Users of automated garages always park and retrieve their cars in well-lit, comfortable transfer areas. Since these are the only areas that users interact with a computerised garage, it is relatively inexpensive for developers to create a luxurious experience for users. Implementing glossy touch screens and user-friendly mobile apps for the quick retrieval of vehicles can make for a comfortable and memorable user experience that they will be willing to pay for.

Another method to overcome the parking problem in universities is by walking campus. It may be difficult for students in Malaysia to do so as the weather is too hot and humid whereby the time student reach the college, it will be though like they have just come out from the shower. However, these problems can be subdued by improving the walking condition. The universities in Malaysia may consider building a shaded walkway for students to walk to their classes and back to their accommodations (Roshandeh \& Puan, 2009). One of the more successful walkways to be built in the canopy walk in Sunway University where the student can get to campus and also shopping mall as the sidewalk is shaded while the trees surrounding the canopy makes the surrounding less humid.

\subsection{Conclusion \& Recommendations}

In conclusion, Taylor's University parking facility does not satisfy the daily needs of the respondents, which are the students. Based on the results of the survey, the respondents are willing to accept any solution that can help improve the parking problem at Taylor's University. The most important solution is to implement a multilevel car park system which can help in terms of quality and the quantity of the parking. The parking facilities should be well maintained to avoid any damages made to the student's vehicle. This would not just benefit the existing user of the parking facilities but also to the future students of Taylor's University. Apart from that, further research could be done to in order to enhance the satisfaction level of the end user towards the parking spaces provided by the Taylor's University.

\section{Acknowledgement}

The authors would like to express their appreciation to everyone involved in the research paper.

\section{References}

Norhisham S, Ismail N. (2008). Case Study on Supply and Demand for University Parking Facilities in College of Engineering UNITEN. In International Conference on Construction and Building Technology. Grand Seasons Hotel, Kuala Lumpur (36): 435-48.

Lim, J. O. (2017). Project Management - Recreation District in Taylor's University Suban... Retrieved from https://www.slideshare.net/Joe_Onn_Lim/projectmanagement-recreation-district-in-taylors-university-subang-jaya-80781688

Wong, J. (2018). Long-delayed KL automated parking system likely to open in early 2019. Retrieved from https://www.carsifu.my/news/long-delayed-kl-automatedparking-system-likely-to-open-in-early-2019.

Siewert, J., \& Siewert, J. (2013). Retrieved from https://blogs.longwood.edu/jaclynsiewert/2013/10/03/cause-and-effect-how-limitations-in-parking-effect-studentsparking-behavior/.

Crowder, M., \& Walton, C. M. (2003). Developing an Intelligent Parking System for The University of Texas at Austin (No. SWUTC/03/167229-1). Southwest Region University Transportation Center, Center for Transportation Research, University of Texas at Austin.

Hildebrand, F., \& Wernli, U. (1995). U.S. Patent No. 5,478,182. Washington, DC: U.S. Patent and Trademark Office. Litman, T. (2006). Parking management. American Planning Association, 40-45.

Litman, T. (2006). Parking management: strategies, evaluation and planning. Victoria Transport Policy Institute.

Pucher, J., Komanoff, C., \& Schimek, P. (1999). Bicycling renaissance in North America?: Recent trends and alternative policies to promote bicycling.Transportation Research Part A: Policy and Practice, 33(7), 625-654.

Qadri, M. T., \& Asif, M. (2009, April). Automatic number plate recognition system for Vehicle identification using optical character recognition. InEducation Technology and Computer, 2009. ICETC'09. International Conference on (pp. 335-338). IEEE.

Rohani, M. M., Wijeyesekera, D. C., \& Karim, A. T. A. (2013). Bus operation, quality Service and the role of bus provider and driver. Procedia Engineering,53, 167-178. 